\title{
Digital Dynamometer and Goniometer in Analyzing Isometric Capacities and Tennis Serving
}

\author{
Chia-Che Liu ${ }^{1,2}$, Chih-Chien Yang ${ }^{2}$, Liang-Ting Tsai ${ }^{3}$, Bi-Fon Chang ${ }^{4}$ Hsiao-Yun Chang ${ }^{5}$, and Chi-Fan Liu ${ }^{1},{ }^{*}$ \\ ${ }^{1}$ Office of Physical Education and Sport Affairs, Feng Chia University, Taichung, Taiwan, R.O.C. \\ ${ }^{2}$ Cognitive Neuro Metrics Laboratory, Graduate Institute of Educational Measurement \& Statistics National Taichung University of \\ Education, Taichung, Taiwan, R.O.C. \\ ${ }^{3}$ Taiwan Marine Education Center, National Taiwan Ocean University, Keenlung, Taiwan, R.O.C. \\ ${ }^{4}$ Department of Physical Education, National Taichung University of Education, Taichung, Taiwan, R.O.C. \\ ${ }^{5}$ School of Physical Therapy, Chung Shan Medical University Rehabilitation, Taichung, Taiwan, R.O.C.
}

\begin{abstract}
The study was to investigate relation between tennis serving techniques and shoulder joint muscles in various skilled players in Taiwan. The study used Micro FET3 (Digital Manual Muscle Dynamometer and Goniometer) which appraised the isometric capacity of the shoulder joint and perimeter muscle. The research consists of 13 collegiate male tennis players; 6 players were in elite groups and the other 7 players were in general groups. The tennis players performed 30 servers testing the range to appraise serve technique reflect. The application of $t$-test and Linear Regression analyzed the serve technique reflect interrelated with the shoulder joint muscle. The muscle strength and the serve accuracy predominate interrelated place where middle trapezius, shoulder internal rotator, and shoulder external rotator of favor hands were obvious. The muscle strength and the serve speed predominated interrelated place where shoulder internal rotator and shoulder external rotator of favor hands were obvious. This study also discovered triceps of favor hands, shoulder extensor, shoulder abductor, triceps, and middle trapezius of non- favor hands muscle strength didn't have any outstanding reference with tennis league table. The research confirmed that the shoulder joint muscle discipline increased shoulder internal rotator, shoulder external rotator, and middle trapezius that help the serve technique reflect. .
\end{abstract}

\section{Introduction}

The tennis players have tonicity muscle that can exert powerful serve technique and avoid sport injuries [1]. The shoulder joint sport injuries are frequent performed power sport of the upper limb movement repeat, such as the serve of the tennis, volleyball, and the flinger of baseball pitch movement [2]. All those sports injuries are more often occurred. Because of the patterns of the sport movement resemblance with one another, the sport injuries in shoulder joints are very similar. Therefore, if a tennis player does not have strong upper limb muscle, it is easy for him/her to get sport injuries. Strength testing is one of the cornerstones of physical examination and an increase in strength is the aim of many rehabilitation programs [3].

Micro FET3 Digital Manual Muscle Dynamometer and Goniometer by Fabrication Enterprises is a unique product used to help in diagnosing and treating muscular disorders. In addition, it allows you to accurately and scientifically measure Muscle Testing (MT) and Range of Motion (ROM). For MT, Micro FET3 offers a true measure of actual force produced. It measures force from multiple directions simultaneously, so even the slightest tip of the transducer won't affect test results. As for ROM, Micro FET3 design uses a single gauge inclinometer that has been used for years in performing ROM tests.
Micro FET3 has the capability of using the latest wireless radio frequency system which eliminates the need for cables, wires or cords, making it completely portable. Weighing less than $1 \mathrm{lb}$, Micro FET3 provides quick, reliable and accurate digital results for muscle and range of motion testing. Besides, it delivers muscle testing accuracy within $2 \%$, and range of motion accuracy within 1 degree, which makes it a useful alternative in sport science research.

\section{Tennis serve technique}

Being capable of serving in high speed doesn't guarantee a tennis player can save the serve game. In other words, though not being able to serve in high speed, a tennis player can raise the odds of saving the serve game by controlling the ball precisely, altering the direction of serving once in a while, serving toward wide, his rival's bodies or center line, which makes it difficult for receivers to predict ball placements[4].

The tennis serve movement drift is divided into five stages- preparative serve movement, back swing movement, toss movement, slash movement, and shotmaking follow -through movement. Serve fundamental stroke technique enact very importance role in the competition. A perfection serve technique can handily win the serve game during the competition. It is basically not failing. This is a tendency of power tennis. The big

Corresponding author: fanchiliu@yahoo.com

C) The Authors, published by EDP Sciences. This is an open access article distributed under the terms of the Creative Commons Attribution License 4.0 (http://creativecommons.org/licenses/by/4.0/). 
league players need possess one of requisite [5]. The tennis competition starts prologue from serve and received. Whereas, the power tennis leads the serve is not just active attack, but also is one of the cage convenience [6]. Therefore, the serve is very importance technique in the tennis sports, also is a singularity grip by oneself, and did not influence by adversary. A lots of male and female tennis players serve constantly created new high speed and time speed over 200 kilometer in the professional tennis now. Nowadays, the professional tennis mechanism tends to be power tennis. Winning linchpin have to be shot-making morality and speed [7]. Consequently, in a professional sport that requires speed and explosive power, a tennis player can boost the odds on winning by making good use of his/her technique. Performing shot-making movement that need in-form grip to retain racket stability from instant hitting, and penetrate body rotate and kinetic chain impact. Ranking of joint is from the leg along the basin, the torso, and the upper limb which speed and power will lastly deliver to the racket and comprise the speed of the racket [8]. The upper limb power movement expression is very important pointer for excellence players. Therein, the upper limb joint movements have ultimate affect on the speed of the ball [9]. Serve is the most important technique in the tennis competition, besides, it is the easiest to incurrence sport injuries.

The serve technique, the ball speed and the angle cannot be entirely concomitant. If the serve has a big angle, than the ball needs aggrandize rotation. The tennis player might increase the rotation of the serve to comprise the height hop and the big angle serve. Thus, it can decrease molarity of the serve, the received backstroke and enhance proximate attack opportunity. This can enhance the percentage of winning. Therefore, the tennis player possess bionic serve accuracy and serve speed. Then the serve technique level will be promoted to great success.

Both the speed of the serve and the elbow extension were related [10]. The different speeds of the serve on the female tennis players. The muscle denomination weight of the elbow extension movement would predominate the dissimilitude [11]. The research proved that the tennis players who could serve fast had elbow joint extensive muscles that were in better condition. This research was to treat the shoulder joint muscle to see whether it was influenced with the serve speed or the serve accuracy.

\section{Method}

The research targets 13 collegiate tennis players and divides them into 2 groups- elite group and general group on the basis of their national ranking of Chinese Taipei Tennis Association. The 6 players whose level ranking are within 32 are labeled elite, while the others are labeled general. All of the players have no severe upper limb injuries within a year and participate in the test voluntarily.

The shoulder muscle strength evaluation is to gauge the isometric strength of shoulder joints and their ambient muscles, including shoulder extensor, shoulder flexor, shoulder abductor, biceps, triceps, serratus anterior, middle trapezius, lower trapezius, shoulder internal rotator (shoulder IR), and shoulder external rotator (shoulder ER) with MicroFET3. All of the test receivers use both their favor hands and non-favor hands in the tests.

The evaluation of serve technique performance is to gauge serve speed with Stalker SPORT Radar Gun (Applied Concepts, Inc., TX). In the research, the definition of "efficient serve" is to serve the ball into designated placements. Figure 2 explains the test of serve speed and accuracy, we divide the sever placements into three blocks- A, B and C.

Every test receiver has to serve 10 balls into each block randomly. If the ball falls in to the designated block, it's called "an efficient ball." The accuracy criterion is based on the percentage of "efficient balls" in every 30 serve. If the sever is "efficient", the searchers will record its speed. If it's inefficient, they won't [12].

This research analyzes the data with the computer statistical software- SPSS for windows 12.0. First, on the basis of independent sample t-test, it assays the difference of shoulder joint muscle strength in favor hands and non-favor hands between elite group players and general group players. And then, with Linear Regression, it analyzes the relativity of shoulder joint muscle strength in both hands and serve speed, serve accuracy. In the research, we set the significance level as $\alpha=.05$.

Table 1. test receivers' personal information

\begin{tabular}{|c|c|c|c|l|}
\hline & age & height & \multicolumn{1}{c|}{ weight } & experience \\
\hline $\begin{array}{c}\text { Elite } \\
(\mathrm{N}=6)\end{array}$ & $8.83 \pm 0.9$ & $173.60 \pm 9.1$ & $65.66 \pm 11.9$ & $10 \pm 1.6$ \\
\hline $\begin{array}{c}\text { General } \\
(\mathrm{N}=7)\end{array}$ & $21 \pm 1.1$ & $175 \pm 4.4$ & $69.20 \pm 5.7$ & $9.85 \pm 1.0$ \\
\hline
\end{tabular}

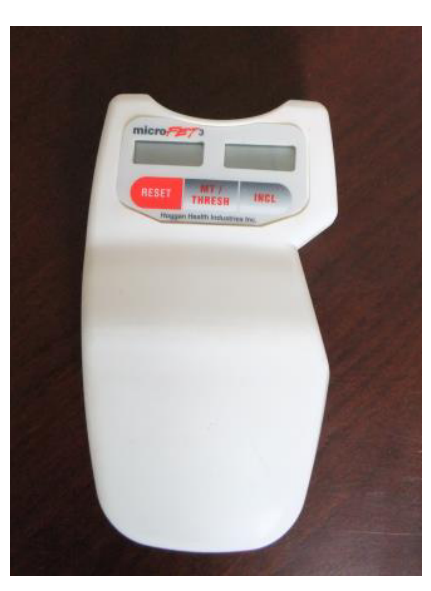

(a) 


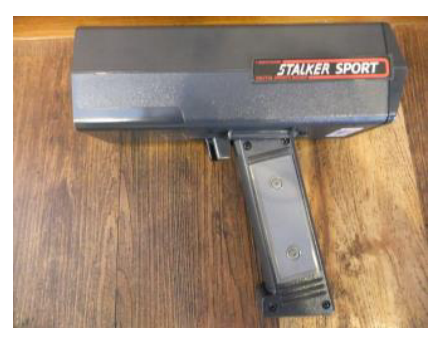

(b)

Fig. 1. (a) Micro FET3 (Digital Manual Muscle Dynamometer and Goniometer) (b) Stalker SPORT Radar Gun

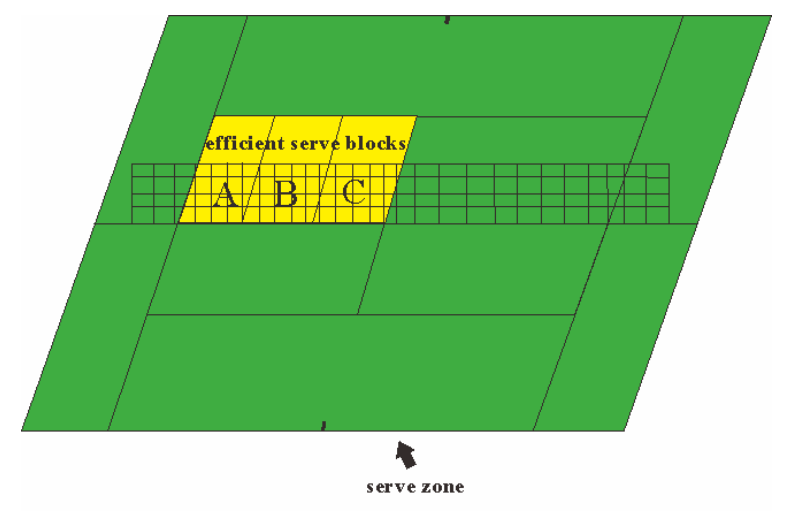

Fig. 2. test on serving techniques performance

\section{Results}

The comparison of shoulder joint muscle strength between the elite players and general ones is shown as Table 2 and 3; the relevance of the players' shoulder joint muscle strength and his serve speed, accuracy is presented as Table 4 and Table 5. On average, the serve accuracy of the elite players is $33 \pm 6.89 \%$; the serve speed is $160 \pm 10.08 \mathrm{~km} / \mathrm{hr}$. As for the general players, the serve accuracy is $23 \pm 11.35 \%$; the serve speed is $161 \pm 9.58 \mathrm{~km} / \mathrm{hr}$. Besides, in the research, we get the ratio of shoulder internal rotation to external rotation. The ratio of shoulder internal rotation to external rotation of elite players is $1.07 \pm 0.15$, while that of general players is $1.16 \pm 0.08$.

According to Table 2, as we compare the elite players' shoulder joint muscle strength of favor hands to that of the general players, we find only "triceps" reaches the outstanding standard $(p<.05)$. The elite players' muscle strength of triceps is $33.57 \pm 5.35$ pounds, while that of the general players is $45.27 \pm 7.93$ pounds. The data shows that the elite players' muscle strength of triceps is inferior to that of the general players. As for the other items on the table, they don't show any significant distinction between the groups.

Table 2. elite and general players shoulder joint muscle strength in favor hands in $t$-test

\begin{tabular}{|c|c|c|c|c|}
\hline variable & groups & mean & SD & T \\
\hline \multirow{2}{*}{$\begin{array}{c}\text { Shoulder } \\
\text { extensor }\end{array}$} & elite & 36.55 & 7.95 & \multirow{2}{*}{-1.93} \\
\cline { 2 - 4 } & general & 43.67 & 5.33 & \\
\hline Shoulder & elite & 36.12 & 6.86 & -2.02 \\
\hline
\end{tabular}

\begin{tabular}{|c|c|c|c|c|}
\hline flexor & general & 42.61 & 4.69 & \\
\hline \multirow{2}{*}{$\begin{array}{l}\text { Shoulder } \\
\text { abductor }\end{array}$} & elite & 36.52 & 10.10 & \multirow{2}{*}{-1.17} \\
\hline & general & 41.39 & 4.26 & \\
\hline \multirow{2}{*}{ Biceps } & elite & 55.52 & 10.25 & \multirow{2}{*}{-1.83} \\
\hline & general & 63.73 & 5.68 & \\
\hline \multirow{2}{*}{ Triceps } & elite & 33.57 & 5.35 & \multirow{2}{*}{$-3.06^{*}$} \\
\hline & general & 45.27 & 7.93 & \\
\hline \multirow{2}{*}{$\begin{array}{l}\text { Serratus } \\
\text { anterior }\end{array}$} & elite & 34.30 & 12.05 & \multirow{2}{*}{-1.42} \\
\hline & general & 43.10 & 10.37 & \\
\hline \multirow{2}{*}{$\begin{array}{l}\text { Middle } \\
\text { trapezius }\end{array}$} & elite & 29.67 & 6.29 & \multirow{2}{*}{-1.60} \\
\hline & general & 34.01 & 3.31 & \\
\hline \multirow{2}{*}{$\begin{array}{l}\text { Lower } \\
\text { trapezius }\end{array}$} & elite & 14.58 & 3.35 & \multirow{2}{*}{-2.15} \\
\hline & general & 19.56 & 4.73 & \\
\hline \multirow{2}{*}{$\begin{array}{c}\text { Shoulder } \\
\text { IR }\end{array}$} & elite & 29.60 & 8.30 & \multirow{2}{*}{-0.56} \\
\hline & general & 31.59 & 3.04 & \\
\hline \multirow{2}{*}{$\begin{array}{c}\text { Shoulder } \\
\text { ER }\end{array}$} & elite & 27.60 & 6.59 & \multirow{2}{*}{0.16} \\
\hline & general & 27.13 & 3.04 & \\
\hline
\end{tabular}

According to Table 3, the elite players and the general ones' muscle strength of shoulder extensor, shoulder abductor, triceps and trap middle in favor hands all reach the outstanding standard $(p<.05)$. The elite players' muscle strength of shoulder extensor is $35.85 \pm 9.15$ pounds, while that of the general players is $45.20 \pm 6.36$ pounds. The data shows that the elite players' muscle strength of shoulder extensor is inferior to that of the general players.

The elite players' muscle strength of shoulder abductor is $34.75 \pm 6.53$ pounds, which shows that the elite players' muscle strength of shoulder abductor is inferior to that of the general players. The elite players' muscle strength of triceps is $33.10 \pm 4.73$ pounds, while that of the general players is $42.20 \pm 7.67$ pounds. The data shows that the elite players' muscle strength of triceps is inferior to that of the general players.

The elite players' muscle strength of middle trap is $25.31 \pm 3.33$ pounds, while that of the general players is $31.96 \pm 2.73$ pounds. The data shows that the elite players' muscle strength of middle trap is inferior to that of the general players. As for the other muscular factors on Table 3, they don't show any significant distinction between the two groups.

Table 3. elite and general players shoulder joint muscle strength in non- favor hands in $t$-test

\begin{tabular}{|c|c|c|c|c|}
\hline variable & groups & mean & SD & T \\
\hline \multirow{2}{*}{$\begin{array}{c}\text { Shoulder } \\
\text { extensor }\end{array}$} & elite & 35.85 & 10.03 & \multirow{2}{*}{$-1.99^{*}$} \\
\cline { 2 - 4 } $\begin{array}{c}\text { Shoulder } \\
\text { flexor }\end{array}$ & general & 45.20 & 6.87 & \\
\cline { 2 - 4 } & elite & 34.73 & 10.12 & \multirow{2}{*}{-1.30} \\
\hline \multirow{2}{*}{$\begin{array}{c}\text { Shoulder } \\
\text { abductor }\end{array}$} & elite & 40.03 & 3.62 & \\
\cline { 2 - 4 } & general & 42.01 & 4.30 & \multirow{2}{*}{$-2.26^{*}$} \\
\hline \multirow{2}{*}{ Biceps } & elite & 48.25 & 7.64 & \multirow{2}{*}{-2.18} \\
\cline { 2 - 4 } & general & 56.20 & 5.48 & \\
\hline Triceps & elite & 33.10 & 5.18 & $-2.32^{*}$ \\
\hline
\end{tabular}




\begin{tabular}{|c|c|c|r|c|}
\hline & general & 42.20 & 8.28 & \\
\hline \multirow{2}{*}{$\begin{array}{c}\text { Serratus } \\
\text { anterior }\end{array}$} & elite & 35.58 & 12.71 & \multirow{2}{*}{-1.38} \\
\cline { 2 - 4 } $\begin{array}{c}\text { Middle } \\
\text { trapezius }\end{array}$ & general & 43.77 & 8.59 & \\
\cline { 2 - 4 } & general & 25.31 & 3.65 & \multirow{2}{*}{$-3.64^{*}$} \\
\hline $\begin{array}{c}\text { Lower } \\
\text { trapezius }\end{array}$ & elite & 13.96 & 2.95 & \\
\cline { 2 - 4 } & general & 15.93 & 1.91 & \multirow{2}{*}{-1.34} \\
\hline $\begin{array}{c}\text { Shoulder } \\
\text { IR }\end{array}$ & elite & 26.25 & 9.52 & \multirow{2}{*}{0.32} \\
\cline { 2 - 4 } & general & 25.03 & 3.41 & \\
\hline \multirow{2}{*}{$\begin{array}{c}\text { Shoulder } \\
\text { ER }\end{array}$} & elite & 26.98 & 6.21 & \multirow{2}{*}{-0.94} \\
\cline { 2 - 4 } & general & 29.96 & 5.16 & \\
\hline \multirow{2}{*}{$*$ p-value $<.05$} & & & \multicolumn{2}{|c}{} \\
\hline
\end{tabular}

Table 4. elite and general players shoulder joint muscle strength in favor hands in Linear Regression

\begin{tabular}{|c|c|c|c|c|}
\hline & \multicolumn{4}{|c|}{ serve accuracy } \\
\hline variable & $\beta$ & SE & $\mathrm{T}$ & $\begin{array}{c}\mathrm{p}- \\
\text { value }\end{array}$ \\
\hline intercept & -81.51 & 44.98 & -1.81 & .21 \\
\hline $\begin{array}{l}\text { Shoulder } \\
\text { extensor }\end{array}$ & -3.49 & 1.21 & -2.88 & .10 \\
\hline Shoulder flexor & -0.43 & 0.50 & -0.85 & .49 \\
\hline $\begin{array}{l}\text { Shoulder } \\
\text { abductor }\end{array}$ & 0.25 & 0.78 & 0.32 & .78 \\
\hline Biceps & 3.59 & 1.33 & 2.71 & .11 \\
\hline Triceps & 0.16 & 0.34 & 0.47 & .69 \\
\hline $\begin{array}{l}\text { Serratus } \\
\text { anterior }\end{array}$ & -3.24 & 0.97 & -3.35 & .08 \\
\hline $\begin{array}{l}\text { Middle } \\
\text { trapezius }\end{array}$ & 8.18 & 1.84 & 4.44 & $.04^{*}$ \\
\hline $\begin{array}{l}\text { Lower } \\
\text { trapezius }\end{array}$ & -6.31 & 1.61 & -3.91 & .06 \\
\hline Shoulder IR & 4.41 & 0.73 & 6.07 & $.03 *$ \\
\hline \multirow[t]{2}{*}{ Shoulder ER } & -4.61 & 0.88 & -5.25 & $.03 *$ \\
\hline & \multicolumn{4}{|c|}{ serve speed } \\
\hline variable & $\beta$ & SE & $\mathrm{T}$ & $\begin{array}{c}\mathrm{p}- \\
\text { value }\end{array}$ \\
\hline intercept & 77.12 & 28.49 & 2.71 & .11 \\
\hline $\begin{array}{l}\text { Shoulder } \\
\text { extensor }\end{array}$ & -0.02 & 0.78 & -0.03 & .99 \\
\hline Shoulder flexor & 0.56 & 0.32 & 1.75 & .22 \\
\hline $\begin{array}{l}\text { Shoulder } \\
\text { abductor }\end{array}$ & -0.23 & 0.49 & -.46 & .69 \\
\hline Biceps & 1.50 & 0.84 & 1.78 & .22 \\
\hline Triceps & 0.77 & 0.21 & 3.63 & .07 \\
\hline $\begin{array}{l}\text { Serratus } \\
\text { anterior }\end{array}$ & -0.88 & 0.61 & -1.43 & .29 \\
\hline $\begin{array}{l}\text { Midddle } \\
\text { trapezius }\end{array}$ & 0.25 & 1.17 & 0.21 & .85 \\
\hline $\begin{array}{c}\text { Lower } \\
\text { trapezius }\end{array}$ & -1.88 & 1.02 & -1.84 & .21 \\
\hline Shoulder IR & -2.36 & 0.46 & -5.14 & $.04 *$ \\
\hline Shoulder ER & 2.99 & 0.56 & 5.37 & $.03^{*}$ \\
\hline
\end{tabular}

$*$ p-value $<.05$

Table 4 and Table 5 are the Linear Regression of shoulder joint muscle strength. The parameters stand for the estimated values of variables and intercepts.

In Linear Regression on serve accuracy, the muscle strength of middle trapezius, shoulder IR, and shoulder ER in favor hands all shows remarkable distinction ( $p$ $<.05)$. As for serve speed, the the muscle strength of shoulder IR and shoulder ER in favor hands both shows remarkable distinction $(p<.05)$. Moreover, in non-favor hands, none of the variables in Linear Regression on serve accuracy and speed shows significant distinction.

Table 5. elite and general players shoulder joint muscle strength in non- favor hands in Linear Regression

\begin{tabular}{|c|c|c|c|c|}
\hline & \multicolumn{4}{|c|}{ serve accuracy } \\
\hline variable & $\beta$ & $\mathrm{SE}$ & $\mathrm{T}$ & $\begin{array}{c}\mathrm{p}- \\
\text { value }\end{array}$ \\
\hline intercept & 96.75 & 33.12 & 2.92 & .10 \\
\hline $\begin{array}{l}\text { Shoulder } \\
\text { extensor }\end{array}$ & 0.49 & 0.99 & 0.50 & .67 \\
\hline Shoulder flexor & 1.97 & 1.96 & 1.01 & .42 \\
\hline $\begin{array}{l}\text { Shoulder } \\
\text { abductor }\end{array}$ & -2.19 & 1.39 & -1.58 & .26 \\
\hline Biceps & 0.32 & 1.54 & 0.21 & .85 \\
\hline Triceps & -1.40 & 1.37 & -1.02 & .42 \\
\hline Serratus anterior & 0.95 & 0.78 & 1.22 & .35 \\
\hline Middle trapezius & -0.43 & 1.69 & -0.25 & .83 \\
\hline Lower trapezius & -0.30 & 1.55 & -0.19 & .86 \\
\hline Shoulder IR & -1.30 & 1.41 & -0.92 & .45 \\
\hline \multirow[t]{2}{*}{ Shoulder ER } & -1.06 & 1.64 & -0.65 & .58 \\
\hline & \multicolumn{4}{|c|}{ serve speed } \\
\hline variable & $\beta$ & SE & $\mathrm{T}$ & $\begin{array}{c}\mathrm{p}- \\
\text { value }\end{array}$ \\
\hline intercept & 142.88 & 24.39 & 5.86 & $.03 *$ \\
\hline $\begin{array}{l}\text { Shoulder } \\
\text { extensor }\end{array}$ & -0.16 & 0.73 & -0.22 & .85 \\
\hline Shoulder flexor & -0.47 & 1.44 & -0.32 & .78 \\
\hline $\begin{array}{l}\text { Shoulder } \\
\text { abductor }\end{array}$ & -1.55 & 1.02 & -1.52 & .27 \\
\hline Biceps & -0.20 & 1.13 & -0.18 & .87 \\
\hline Triceps & 1.82 & 1.01 & 1.80 & .21 \\
\hline Serratus anterior & -0.78 & 0.58 & -1.35 & .31 \\
\hline Middle trapezius & -0.64 & 1.24 & -0.51 & .66 \\
\hline Lower trapezius & -0.39 & 1.14 & -0.34 & .77 \\
\hline Shoulder IR & -0.56 & 1.04 & -0.54 & .64 \\
\hline Shoulder ER & 3.94 & 1.21 & 3.26 & .08 \\
\hline
\end{tabular}

\section{Conclusion}

In general, elite tennis players have high-speed and efficient serve technique. And their shoulder muscle strength is highly related to their serve movements, ground strokes, net interception, etc. Hence, to give full play of one's muscle strength in high speed, especially when $s /$ he accelerates a racket, high-energy power in shoulder joints is required, which is an important index in racket sports [13].

According to the research, the strength of triceps of favor hands, shoulder extensor, shoulder abductor, triceps and middle trapezius of non-favor hands of elite players is remarkably minor to that of general players, while statistics on other muscles doesn't show much 
distinction. The results of this research are different from the prior studies [14][15][16].

The researchers ascribe the outcome to the fact that tennis is a sport requiring whole-body coordination and pliability, not just focusing on the training of a few parts. Besides, the researchers presume the decline of muscle strength in elite players is because they attain more training and attend more tournaments, which causes fatigue. We suggest more research be done on the training of elite tennis players and their counterparts.

The shoulder joint muscle affects the serve reflect of the tennis players. The consequences of this investigation figures out the serve accuracy domain were predominately interrelated when overused hand, middle trapezius, shoulder internal rotator and shoulder external rotator. The serve speed domain were predominately interrelated when overused hand, shoulder internal rotator and shoulder external rotator, the shoulder internal rotators were a very important linchpin with the control of the serve falling point [15]; because trapezius at the launch process attach tranquilize muscle and can decrease scapula drag ahead.

This manifest trapezius at the launch movement keeps the shoulder joint steady which was very important [17]. Other research results were similar to these results. This research result shows that the shoulder joint muscle of the tennis players in the elite group's serve techniques, had an accuracy average of $33 \pm 6.89 \%$ better than the tennis players in the general group's serve which averaged $23 \pm 11.35 \%$. This manifest the tennis player's serve accuracy and the shoulder joint muscle are not exactly interrelated. However, the tennis serve technique requires height mechanism movement, also needs to consider the integer profluent movement and the time of the body center gravity displacement. This has to cooperate with the release integer swing arm.

The serve will amplify efficiency culmination. The shoulder joint rotator can contribute to the ball speed $71 \%$ and can generate important effort on the ball [18]. To improve serving technique, tennis players should enhance their whole-body physical coordination and aptly increase the training on middle trapezius, shoulder internal rotator and shoulder external rotator, etc. In conclusion, in current power tennis age, tennis players pay more attention on the accuracy of serve technique. They not only care about the speed, quality and quantity of ball serving but the ball placements, angles, and twirling. Current professional tennis players have better figure and skills; however, they won't be able to control the game or their opponents without accurate ball placements when they serve.

According to the research, we find high relativity between enhancing the training of shoulder internal rotator and shoulder external rotator and the speed and accuracy of serving, which pinpoints via full-scale muscle training, improving serve technique and reducing the probability of getting hurt are crucial to professional tennis players.

\section{References}

1. B. C. Elliott, "Biomechanies of the Serve in Tennis. A Biomedical Perspective. Sports Medicine, 6, 285294 (1988)

2. H. W. Lee, "Mechanisms of Neck and Shoulder Injuries in Tennis Player. The Journal of Orthopaedic and Sports Physical Therapy, 21, 28-37 (1995)

3. A. S. Falrey, K. S. Courneya, and C. J. Field, "Physical Exercise and immune system function in Cancer survivors. Cancer. 94(2), 539-551 (2002)

4. H. S. Wang, W. Y. Lin, and H. H. Chao, "The role of serve placement in Tennis matches- An example study of the 2004 US Open Men's Singles. Physical Education Journal, 38(4),109-120 (2005)

5. Y. H. Lien, "A qualitative study on modern man Power Tennis. Physical Education Journal, 37,113131 (2004)

6. B. F. Chang, C. J. Chen, "Outcome Analysis of Skills Serve and Receive Among Professional Tennis Players. Sports Coaching Science, 16, 83-94 (2009)

7. I. T. Wang, "Sports Biomechanical Analysis of the Flat Service in Tennis. Taipei Physical Education College Institute of Sports and Exercise Science Master's Thesis (2007)

8. B. Elliott, "Biomechanics and tennis. British Journal of Sports Medicine, 40, 392-396, (2006)

9. C. M. Chen, W. T. Tang, "The Correlation Data of Upper Lime Muscle for Baseball Pitcher Exerted discipline. The University Physical Education \& Sports. 75, 61-67 (2004)

10. M. W. Huang, L. C. Liang, and C. J. Chen, "The Correlation of the Serve to the Shoulder and Elbow Joint Muscle for Female Tennis Player. Physical Education, Fitness and Inactive Periodical of Nation Chiayi University, 9(1), 127-132 (2010)

11. L. C. Liang, "Upper Limb Isokinetic Strength for Tennis Players with Different Serve Velocities. Sports \& Exercise Research, 13(2), 181-187 (2011)

12. B. F. Chang, "Relationship between balance and serve skill for collegiate tennis players. Physical Education Journal. 44(1),.45-56 (2011)

13. L. H. Wang, "The Application of Physiology to Tennis. The University Physical Education \& Sports, 55,.127-132 (2001)

14. S. L. Huang, "Isokinetic analysis of shoulder muscles in three levels of women tennis players. Chinese Culture University Institute of sports coaching science Master's Thesis (1996)

15. M. W. Huang, "The Differences of Upper Isokinetic Strength Profile and Specific Performance between Elite and General Female Tennis Players. National Hsinchu University of Education Institute of Physical Education Master's Thesis (2009)

16. A. Stanley, R. McGann, J. Hall, L. Mckenna, and N. K. Briffa, "Shoulder strength and range of motion in female amateur-league tennis players. The Journal of Orthopaedic \& Sports Physical Therapy, 34,.402409 (2004) 
17. Y. C. Liu, S. H. Chen, and H. Y. Chen, "The Electromyography Analysis of Grenade Throwing. Journal of Physical Education and Sports, 16(3), 205-218 (2005)

18. A. S. Clements, K. A. Ginn, and E. Henley. "Correlation between muscle strength and throwing speed in adolescent baseball players. Physical Therapy in Sport, 2.123-131 (2001) 